\title{
Preliminary Study on Pelletization of Oil Palm Empty Fruit Bunches (EFB)/Spent Activated Carbon (AC): Effect of Mixing and Adhesive Ratio
}

\author{
K. Y. Teo, S Ghazali, and S. Abd Rahim* \\ Faculty of Chemical and Process Engineering Technology, College of Engineering Technology, Universiti Malaysia Pahang, 26300 Pahang, \\ Malaysia.
}

ABSTRACT - Non-renewable resources such as fossil fuels could be combusted for energy and electricity to human kind. The demand of fossil fuel energy had reached an exponential growth which caused disasters and catastrophic damages on the environment; thus, renewable resources should be implemented to protect the environment. One of the natural resources was biomass waste. In this study, spent activated carbon (AC) was co-pelletized with biomass waste, oil palm empty fruit bunches (EFB). The effect of EFB, AC and adhesive (tapioca) mixing ratio in the pellet was evaluate through physical and thermal properties. The raw materials were grinded and mixed together at different $A C / E F B / t a p i o c a$ ratio. The mixed raw materials were compressed at $130^{\circ} \mathrm{C}$ and $7 \mathrm{MPa}$ for 10 minutes. The densified products were characterized by using Thermogravimetric Analysis (TGA). For the thermal characteristics, sample with $0 \%$ waste AC, 90\% EFB and 10\% starch had the highest mass loss rate $(570 \mu \mathrm{g} / \mathrm{min})$ followed by sample with $10 \%$ of waste $A C$, $60 \%$ of EFB and $30 \%$ of starch which was $420 \mu \mathrm{g} / \mathrm{min}$. Besides, sample with $0 \%$ waste $\mathrm{AC}, 90 \%$ EFB and $10 \%$ had the highest burn out temperature $\left(802.6^{\circ} \mathrm{C}\right)$ followed by sample with $30 \%$ of waste $\mathrm{AC}, 60 \%$ of EFB and $10 \%$ of starch which was $792.85^{\circ} \mathrm{C}$. In conclusion, sample with $0 \%$ waste $\mathrm{AC}, 90 \%$ EFB and $10 \%$ starch had an easiest ignition and longest combustion period since it had the highest mass loss rate and burn out temperature.
ARTICLE HISTORY

Received: 14 March 2021

Revised: 28 April 2021

Accepted: 29 April 2021

\section{KEYWORDS}

Co-pelletization

Empty fruit bunches

Waste activated carbon

Thermal stability

\section{INTRODUCTION}

Biomass energy is the solar energy that is stored in plants and animals or in the wastes that are produced. This energy can be recovered by burning biomass as fuel [1]. The average majority of biomass energy is produced from wood and wood wastes (64\%), followed by solid waste (24\%), agricultural waste (5\%), and landfill gases (5\%) [2]. One of the agricultural wastes is oil palm empty fruit bunches (EFB). EFB is the waste generated from the palm oil extracting process. Due to its availability in Malaysia, oil palm waste is the best to be used as biomass waste. In 2019, Malaysia was one of the producers of palm oil, producing 17.73 million tonnes, or $29.5 \%$ of the world total production.

Previous research and commercialization activities have indicated that EFB has been subjected to produce numerous products such as bio-syngas, bio-oil, bio-hydrogen, briquette and pellet fuels, bio-ethanol, and activated carbon [3, 4]. Moreover, these EFBs are also used as fuels to generate energy. EFB generates the most power among the other byproducts from the palm oil mill industry. According to Sarawak Energy, EFB has generated a total of $125 \mathrm{MW}$ of electricity which is higher than fiber (112 MW), shell (98 MW), and palm oil mill effluent (POME) (40 MW).

Activated carbons (AC) are the most versatile and commonly used adsorbents because of their extremely high surface areas micropore volumes, large adsorption capacities, fast adsorption kinetics and relatively ease of regeneration. In the pharmaceutical area, the chemical activated carbon with iron (III) chloride is used to adsorb antipyrine from wastewater treatment plants [5]. Besides, in the biogas production area, bio-methane is adsorbed from anaerobic digestion by using $\mathrm{AC}$ [6]. Furthermore, in the mining field, $\mathrm{AC}$ is also useful in the adsorptive removal of sulfate from acid mine drainage. However, once contaminants concentrate on the active bonding sites and the AC becomes saturated, it is replaced with fresh activated carbon, and spent AC is usually incinerated.

Restoring the adsorption capacity, referred to as AC regeneration, might involve heating in steam or nitrogen $\left(\mathrm{N}_{2}\right)$ at a given temperature for an adequate length of time or the use of stirring electrochemical reactors. Depending on the substances adsorbed that need to be removed, some solvents, acids, and alkalis might be employed. Regeneration is therefore an energy-intensive and relatively expensive option. Regeneration efficiency, however, decreases after some cycles and deterioration of the regenerated adsorbent's porosity and serious carbon weight losses [7].

According to Isla-Cabaraban [8], spent AC or waste AC could be used in cofiring with coal which is an economical method for waste disposal while recovering energy from the heat of combustion. From the study of [9], sewage sludge was co-pelletized with biomass and the pellet showed its potential in power generation. Hence, in this study, EFB (biomass) and waste $\mathrm{AC}$ will be co-pelletized due to their potential in generating energy. 
Pelletization is referred to an agglomeration process that compresses fine powder or granules of dried biomass into small, spherical, or semi-spherical pellets under high pressure. According to the study of Jiang et.al, the density of pellet was increased when the pressure was increased since the solid particles became closer. In view of the effect of material ratio, when the ratio of material that adds to the biomass increased, the density of pellet increased. This is proved in the study of Jiang and co-workers, when the ratio of sludge is increased, the density of co-pelletized pellet increased. In terms of temperature, as reported by Gilbert et al., the densified pellet density was increased from $50{ }^{\circ} \mathrm{C}$ to $110{ }^{\circ} \mathrm{C}$. However, attention should be paid to a slight decrease in pellet density when the temperature at $125^{\circ} \mathrm{C}$. The appropriate moisture content for co-pelleting is $10-15 \%$ and peaked at $15 \%$. On the other hand, when the biomass size is decreased, the pellet density is increased [10].

The main objective of this paper was to determine the effect of the AC/EFB/Tapioca ratio in pellet physical properties with different material and adhesive ratios. The thermal properties of EFB and pelletized samples were analyzed by thermogravimetric analysis (TGA) [11].

\section{MATERIALS AND METHODS}

\section{Raw Materials Collection}

The spent activated carbon was collected at an industry in Kerteh, Terengganu while the EFB was collected at Lepar. Both samples were dried prior for experimental use. For the adhesive, commercial tapioca flour was chosen and prepared.

\section{Sample Preparation}

EFB was ground by SIMA FG 400 X 200 Grinder with a mesh size of $2 \mathrm{~mm}$. The size of ground EFB was lower than $2 \mathrm{~mm}$. Ground EFB was placed in a stack of sieves arranged from the largest to the smallest openings. The sieve sizes used were 800, 630, 500, 355, 250, and 106 microns. The set of sieves were placed on the Retsch AR 200 sieve shaker. The duration of the sieving process was $10 \mathrm{~min}$ and the amplitude was $3.0 \mathrm{~m} / \mathrm{mg}$. The particle size of EFB that below 106 microns was chosen for material mixing.

\section{Mixing of Co-Pelletization Sample}

The samples for the co-pelletization process were prepared as in Table 1. The raw materials were mixed according to the ratios by blending. The estimated density of the pellet is $700 \mathrm{~kg} / \mathrm{m}^{3}$, with the volume of the pellet is $7.85 \mathrm{~cm}^{3} \mathrm{obtained}$ from the mold design. The raw material mixture was sprayed with 25 times of water using a spray bottle during the mixing process.

Table 1. Sample ratio for each pellet sample

\begin{tabular}{cccc}
\hline & \multicolumn{4}{c}{ AC/EFB Ratio } \\
Sample & Waste AC & Ratio (\%) \\
\cline { 2 - 4 } & 0 & EFB & Tapioca \\
\hline 1 & 10 & 90 & 10 \\
\hline 2 & 20 & 80 & 10 \\
\hline 3 & 30 & 70 & 10 \\
\hline 4 & & 60 & 10 \\
\hline 1 & 10 & 90 & 0 \\
\hline 2 & 10 & 80 & 10 \\
\hline 3 & 10 & 70 & 30 \\
\hline 4 & 10 & 60 & 20 \\
\hline
\end{tabular}

The blended raw mixture was inserted and pre-compressed manually into mould. The pre-compressed raw mixture in mould was compressed at a temperature of $130{ }^{\circ} \mathrm{C}$ and pressure of $7 \mathrm{MPa}$ for 10 minutes using Lotus Scientific LS-22025 25 Ton Hot and Cold Moulding Press. After the compression process was completed, the densified mixture was cooled under room temperature [12].

\section{Characterization of Raw Materials and Pelletized Sample}

Thermogravimetric analysis was performed to determine the thermal properties of the raw EFB and pelletized sample. The thermal stability data were collected on a Hitachi STA 7000 thermogravimetric analyzer under linear temperature conditions. The temperature was swept from $50^{\circ} \mathrm{C}$ to $800^{\circ} \mathrm{C}$ for samples of $10-15 \mathrm{mg}$ placed in an aluminium pan at a heating rate of $10^{\circ} \mathrm{C} / \mathrm{min}$ under nitrogen atmosphere [11].

The actual density of the pellet was determined after the pellet was dried by using Equation 1 . The Wc was referred to the mass of dried sample and crucible while Wa was referred to the mass of crucible.

$$
\text { Actual density }\left(\frac{\mathrm{kg}}{\mathrm{m}^{3}}\right)=\frac{W c-W a}{1000 \times \text { Volume pellet }}
$$




\section{EXPERIMENTAL RESULTS}

\section{Physical Appearance of the Pelletized Sample}

The physical appearance of pelletized samples was illustrated in Figure 1. The mixtures of different ratios were able to produce a compact and maintain in shape of pellet. This indicate that the optimum amount of moisture and pressure supplied during the pressing process. In addition, an optimum moisture content in pellets improves densification characteristics by increasing bonding via van der Waal's forces.
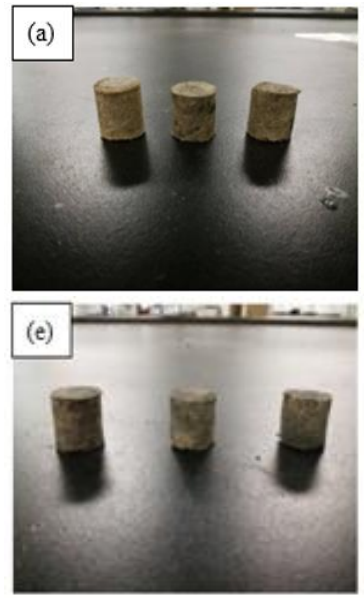
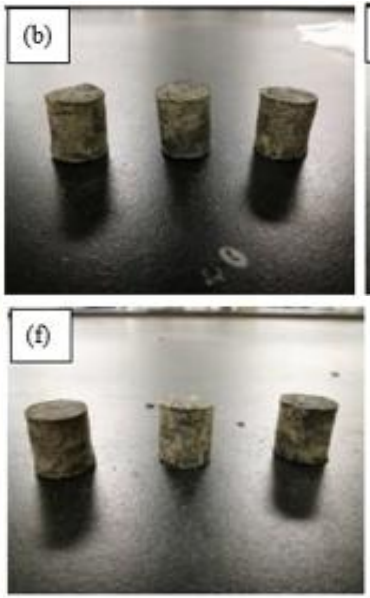
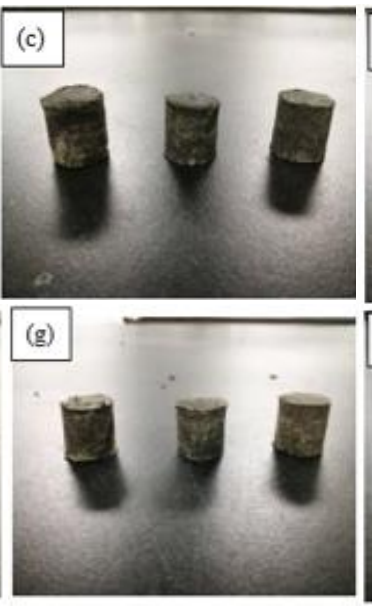

(d)
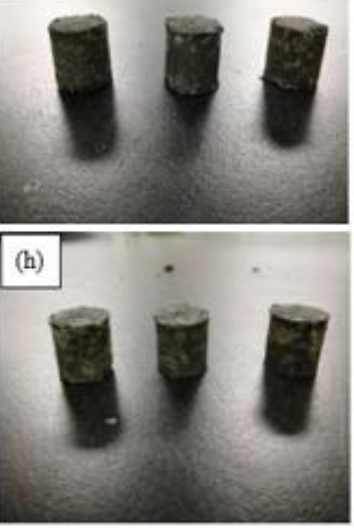

Figure 1. Pelletized samples noted by waste AC: EFB: Tapioca (a) 0\%: 90\%: 10\% (b) 10\%: 80\%: 10\% (c) $20 \%: 70 \%$ : 10\% 3 (d) 30\%: 60\%: 10\% (e) 10\%: 90\%: 0\% (f) 10\%: 80\%: 10\% (g) 10\%: 70\%: 20\% (h) 10\%: 60\%: $30 \%$.

\section{Actual Pellet Density}

Figure 2 shows that as the mass ratio of EFB for both AC/EFB and EFB/Adhesive ratios factors increased, the pellet density decreased and agreed well with the previous reported work [13]. The pellets made from lower particle size exhibited higher density for all biomass. In this study, the lower ratio of EFB in the pellet would result in a higher pellet density. This probably due to the lower ratio of EFB in the pellet will lower the average particle size of biomass in the pellet. The smaller average particle size of biomass could yield a high surface area of contact to form bonds or solid bridges during the compaction process and finally produce higher density pellets [14]. Although the mass ratio of starch is increasing in the EFB/Adhesive ratio factor, there is no noticeable effect of starch content on the individual pellet density [15].

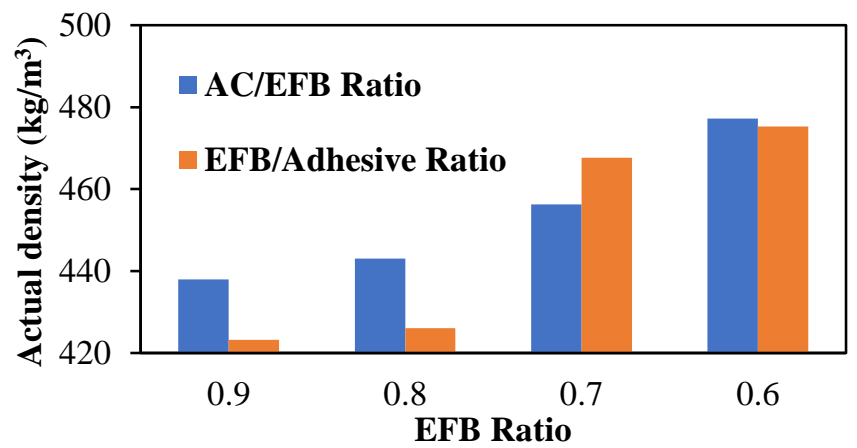

Figure 2. Effect of EFB ratio on the actual pellet density.

\section{Thermal Properties of PHA/NCF Composite}

Thermogravimetric analysis is an important method to understand the thermal stability and combustibility of fuels for subsequent application in combustion facilities. TG and DTG profiles of densified pellets with different material and adhesive ratios were shown in Figures 3 and 4.

From TG curves in Figure3, the first stage corresponds to moisture and very light volatile matter content in the samples is eliminated at a temperature ranging from ambient temperature to $250{ }^{\circ} \mathrm{C}$. At this stage, there were identical among samples from raw $\mathrm{EFB}$ and different $\mathrm{AC} / \mathrm{EFB}$ and $\mathrm{EFB} / \mathrm{Adhesive}$ ratios. The second stage was indicated by a rapid weight loss beginning at $250{ }^{\circ} \mathrm{C}$ to $350{ }^{\circ} \mathrm{C}$ which occurred from the decomposition of hemicellulose common content of lignocellulosic biomass components. The third stage was observed from the change of a rate of mass loss at a temperature 
around $350{ }^{\circ} \mathrm{C}$ to $795{ }^{\circ} \mathrm{C}$ for all samples except for samples with $0 \%$ of waste AC, $90 \%$ of EFB, and $10 \%$ of starch, until $800^{\circ} \mathrm{C}$. After that, the rate of mass loss would remain constant at the fourth stage, where the carbon content has burnout [16].

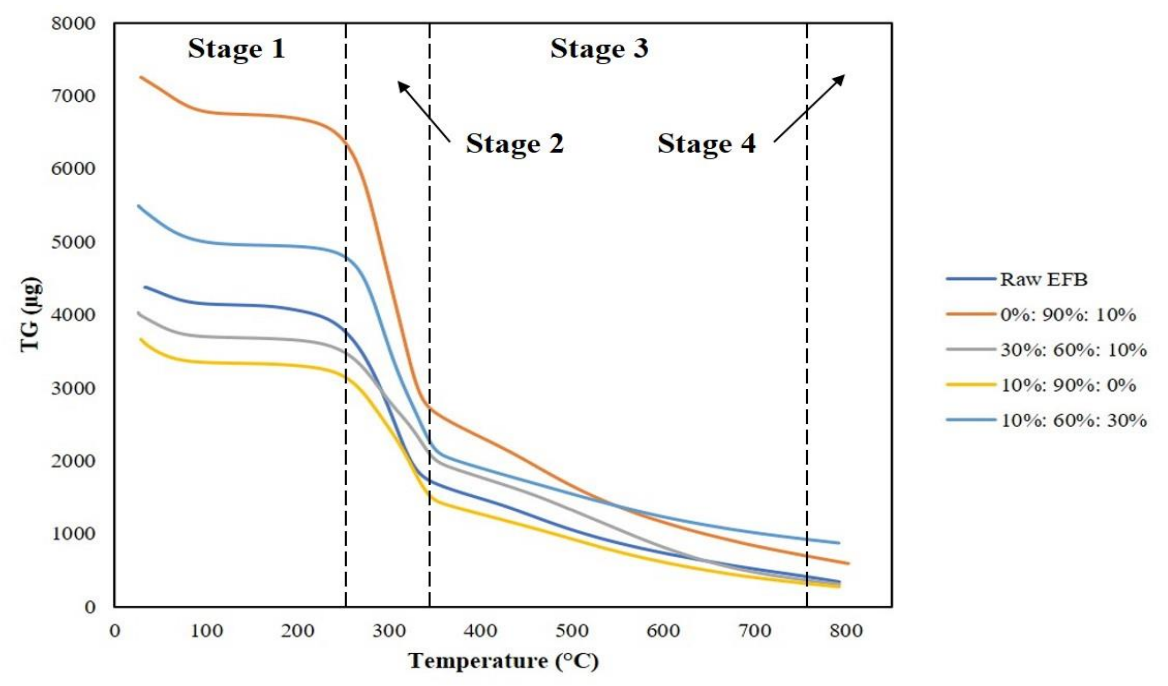

Figure 3. TG curves of raw EFB and pelletized samples of different material and adhesive ratio noted as waste AC: EFB: tapioca

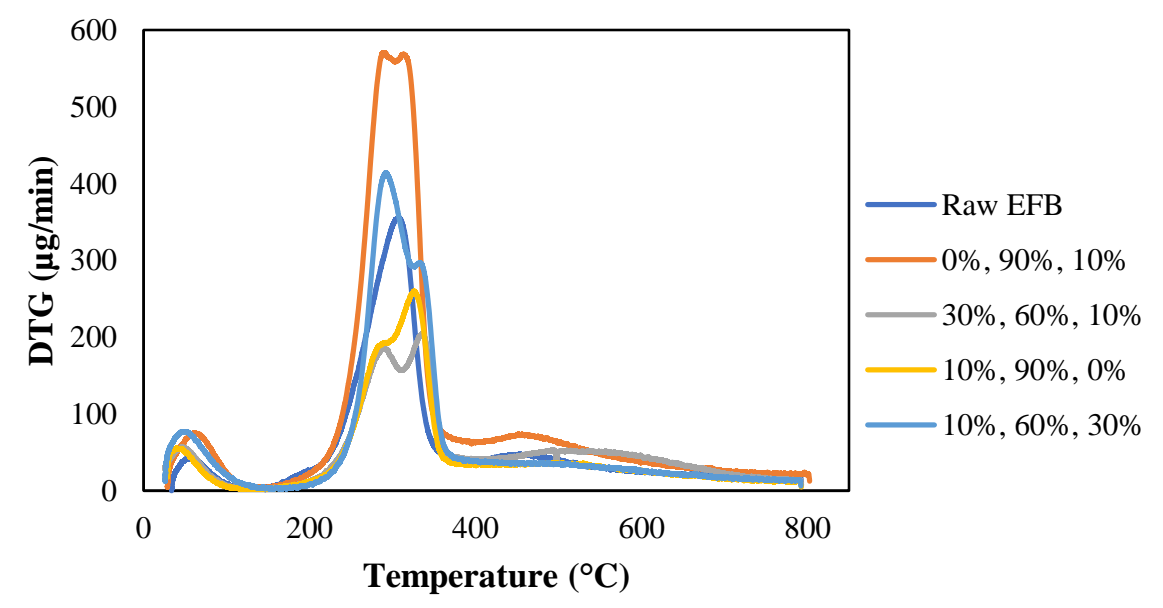

Figure 4. DTG curves of raw EFB and pelletized samples of different material and adhesive ratio waste; AC: EFB: tapioca

On the DTG curves shown in Figure 4, the temperatures at which the maximum rate of weight loss occurred are indicated by the position of peaks in the curve. The four distinct peaks were observed which corresponds to four different changes in the slope of TG curves. The characteristics of three peaks during the combustion process of each material and adhesive ratios were summarized and shown in Table 2. The highest mass loss rate was obtained from a sample with $0 \%$ of waste $\mathrm{AC}, 90 \%$ of $\mathrm{EFB}$, and $10 \%$ of starch which provide an easier ignition.

The burnout temperature, $\mathrm{T}_{\mathrm{b}}$ which is shown in Table 2 is the temperature where the rate of weight lost consistently decrease to less than $1 \%$ per min or when $99 \%$ of the combustible materials have been burnt out [17]. Sample with $0 \%$ of waste $\mathrm{AC}, 90 \%$ of EFB, and $10 \%$ of starch was provided the highest burnout temperature which was $802.6{ }^{\circ} \mathrm{C}$. The higher burnout temperature indicating the longer the combustion period requires.

Table 2. Thermal characteristics of raw EFB and pelletized sample at different AC/EFB/Tapioca ratios

\begin{tabular}{lcccc}
\hline Sample & $\begin{array}{c}\mathbf{T}_{\mathbf{p} 1}\left({ }^{\circ} \mathbf{C}\right) / \mathbf{m a x} \text { rate } \\
(\boldsymbol{\mu g} / \mathbf{m i n})\end{array}$ & $\begin{array}{c}\mathbf{T}_{\mathbf{p} 2}\left({ }^{\circ} \mathbf{C}\right) / \mathbf{m a x} \text { rate } \\
(\boldsymbol{\mu g} / \mathbf{m i n})\end{array}$ & $\begin{array}{c}\mathbf{T}_{\mathbf{p} 3}\left({ }^{\circ} \mathbf{C}\right) / \mathbf{m a x} \text { rate } \\
(\boldsymbol{\mu g} / \mathbf{m i n})\end{array}$ & $\mathbf{T}_{\mathbf{b}}\left({ }^{\circ} \mathbf{C}\right) /$ \\
\hline Raw EFB & $55.32 / 43.48$ & $357.45 / 360$ & $458.57 / 52.17$ & 792.73 \\
0:90:10 & $68.09 / 76.52$ & $314.89 / 570$ & $462.86 / 78.26$ & 802.58 \\
30:60:10 & $42.55 / 69.57$ & $340.43 / 205.71$ & $557.14 / 56.52$ & 792.85 \\
10:90:0 & $42.55 / 69.57$ & $327.66 / / 270$ & $540 / 39.13$ & 792.63 \\
10:60:30 & $51.06 / 78.26$ & $293.62 / 420$ & $531.43 / 39.13$ & 792.16 \\
\hline
\end{tabular}




\section{CONCLUSION}

In conclusion, the higher EFB ratio or content in the pellet was increased, the actual pellet density would decrease. This was because the higher amount of EFB would increase the average particle size of the pellet and reduced the pellet density. Furthermore, the sample with $0 \%$ of waste AC, $90 \%$ of EFB, and $10 \%$ of starch had the longest combustion period since it had the highest burn out temperature which was $802.6{ }^{\circ} \mathrm{C}$. Besides, a sample with $10 \%$ of waste $\mathrm{AC}, 60 \%$ of EFB, and $30 \%$ of starch were the second easiest of ignition because it had the second-highest of mass loss rate which was $420 \mu \mathrm{g} / \mathrm{min}$, while the sample with $30 \%$ of waste AC, $60 \%$ of EFB and $10 \%$ of starch was the second-longest of combustion period because it had the second-highest of burn out temperature which was $792.85^{\circ} \mathrm{C}$. The study shows that the addition of $\mathrm{AC}$ has not given a significant impact to the burnout temperature as the value is just about similar to the raw EFB.

\section{REFERENCES}

[1] S. Tewfik "Biomass utilization facilities and biomass processing technologies", 2004.

[2] A. Demirbas, "Recent advances in biomass conversion technologies", 2000.

[3] P. Lahijani, and Z. A. Zainal, "Gasification of Palm Empty Fruit Bunch in a Bubbling Fluidized Bed: A Performance and Agglomeration Study", Bioresour. Technol., vol. 102, pp. 2068-2076 ,2010, doi: 10.1016/j.biortech.2010.09.101.

[4] A. A. Salema, and F. N. Aini, "Pyrolysis of Oil Palm Empty Fruit Bunch Biomass Pellets using Multimode Microwave Irridation", Bioresour. Technol., vol. 125, pp. 102-107, 2012, doi: 10.1016/j.biortech.2012.08.002.

[5] J. Bedia, C. Belver, S. Ponce, J. Rodriguez, and J. J. Rodriguez, "Adsorption of antipyrine by activated carbons from FeCl3activation of Tara gum", Chem. Eng. J., vol. 333, pp. 58-65, 2018, doi: 10.1016/j.cej.2017.09.161.

[6] M. Farooq, A. H. Bell, M. N. Almustapha, and J. M. Andresen, "Bio-methane from an-aerobic digestion using activated carbon adsorption", Anaerobe, vol. 46, pp. 33-40, 2017 doi: 10.1016/j.anaerobe.2017.05.003.

[7] M. Cheng, S. Yang, and S. Hsieh, "Thermal regeneration of activated carbons exhausted with phenol compound", Sep. Sci. Technol., vol. 42, pp. 639-652, 2007, doi: 10.1080/01496390601070059.

[8] M. T. Isla-Cabaraban, and G. M. S. Cabaraban, "Generating electricity from spent activated carbon: Life cycle environmental benefits", WSEAS Transactions on Environment and Development, pp. 12, 2016.

[9] L. B. Jiang, X. Z. Yuan, Z. H. Xiao, J. Liang, H. Li, L. Cao, H. Wang, X. H. Chen, and G. M. Zeng,"A Comparative Study of Biomass Pellet and Biomass-sludge Mixed Pellet: Energy Input and Pellet Properties", Energy Conversi. Manag., vol. 126, pp. 509-515, 2016, doi: 10.1016/j.enconman.2016.08.035.

[10] L. B. Jiang, J. Liang, X. Z. Yuan, H. Li, C. Li, Z. H. Xiao, H. J. Huang, H. Wang, and G.M. Zeng, "Co-pelletization of Sewage Sludge and Biomass: The Density and Hardness of Pellet", Bioresour. Technol., vol. 166, pp. 435-443, 2014, doi: 10.1016/j.biortech.2014.05.077.

[11] A. F. Owolabi, A. Ghazali, A. Hassan, R. Arjmandi, M. R. N. Fazita, and M. K. M. Haafiz, "Isolation and characterization of microcrystalline cellulose from oil palm fronds using chemomechanical process", J. Society Wood Sci. Technol., vol. 48, pp. 1-11, 2016, doi: 10.1016/j.carbpol.2013.01.035.

[12] K. A. Jeffri, Investigation on the pellet size and adhesive ratio towards the production of Kenaf pellet, 2016

[13] K. J. Moscicki, L. Niedzwiecki, P. Owczarek, and M. Wnukowski, "Commoditization of biomass: Dry torrefaction and pelletization- A review", J. Power Technol., vol. 94, pp. 233-249,2014.

[14] A. Zafari, and M. H. Kianmehr, "Effect of raw material properties and die geometry on the density of biomass pellets from composted municipal solid waste", BioResources, vol. 7, pp. 4704-4714, 2012, doi: 10.15376/BIORES.7.4.4704-4714.

[15] M. Stahl, J. Berghel, S. Frodeson, K. Granstrom, and R. Renstrom, "Effects on pellet properties and energy use when starch is added in the wood-fuel pelletizing process", Energy Fuels, vol. 26, pp. 1937-1945, 2012, doi: 10.1021/ef201968r.

[16] C. H. N Hazirah, M. Masturah, M. and H. Osman, "Preliminary study on analysis of the chemical compositions and characterization of empty fruit bunch (EFB) in Malaysia", Adv. Mat. Res., vol. 970, pp. 204-208, 2014.

[17] P. Zhao, S. Ge, and K. Yoshikawa. "An orthogonal experimental study on solid fuel production from sewage sludge by employing steam explosion", Appl. Energy, vol. 112, pp. 1213-1221, 2013, doi: 10.1016/j.apenergy.2013.02.026. 